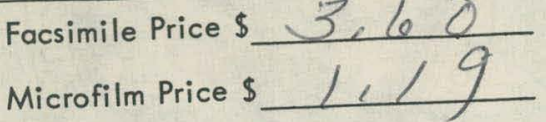

Available from the

Office of Technical Services

Department of Commerce

Washington 25, D. C.

\section{OAK RIDGE NATIONAL LABORATORY}

operated by

UNION CARBIDE CORPORATION

for the

\section{U.S. ATOMIC ENERGY COMMISSION}

\title{
NOTES ON THE LIQUID-METAL BOILING PHENOMENON
}

A. I. Krakoviak

ORNL - TM- 618
COPY NO. - / $/ 99$
DATE - JUIY 10, 1963

ABSTRACT

A brief review of boiling for ordinary fluids with emphasis on the wall superheat required for bubble initiation from different surfaces at varying pressures is presented. Calculations based on an equation valid for normal fluids indicate that superheats from two to eight times that for water are required to initiate a vapor bubble in some of the alkali metals. This high superheat and the high thermal conductivity peculiar to liquid metals are combined to explain the unstable liquid-metal boiling phenomenon in natural- and forcedcirculation loops.

Forced-convection boiling-potassium heat-transfer coefficients correlated by the Lockhart-Martinelli two-phase flow parameter are in reasonable agreement with the forced-convection boiling-water data of Dengler and Addoms.

Some recommendations on bubble initiation sites and future work with liquid metals are also included.

\section{NOTICE}

This document contains information of a preliminary nature and was prepared primarily for internal use at the Oak Ridge National Laboratory. It is subject to revision or correction and therefore does not represent a final report. The information is not to be abstracted, reprinted or otherwise given public dis. semination without the approval of the ORNL patent branch, Legal and Information Control Department. 


\section{DISCLAIMER}

This report was prepared as an account of work sponsored by an agency of the United States Government. Neither the United States Government nor any agency Thereof, nor any of their employees, makes any warranty, express or implied, or assumes any legal liability or responsibility for the accuracy, completeness, or usefulness of any information, apparatus, product, or process disclosed, or represents that its use would not infringe privately owned rights. Reference herein to any specific commercial product, process, or service by trade name, trademark, manufacturer, or otherwise does not necessarily constitute or imply its endorsement, recommendation, or favoring by the United States Government or any agency thereof. The views and opinions of authors expressed herein do not necessarily state or reflect those of the United States Government or any agency thereof. 


\section{DISCLAIMER}

Portions of this document may be illegible in electronic image products. Images are produced from the best available original document. 
This report was prepared as an account of Government sponsored work. Neither the United States, nor the Commission, nor any person acting on behalf of the Commission:

A. Makes any warranty or representation, expressed or implied, with respect to the accuracy, completeness, or usefulness of the information contained in this report, or that the use of any information, apparatus, method, or process disclosed in this report may not infringe privately owned rights: or

B. Assumes any liabilities with respect to the use of, or for damages resulting from the use of any information, apparatus, method, or precess disclosed in this report.

As used in the above, "person acting on behalf of the Commission" includes any employee or contractor of the Commission, or employee of such contractor, to the extent that such employee or contractor of the Commission, or employee of such contractor prepores, disseminates, or provides access to, any iaformation pursuant to his employment or contract with the Commission, or his employment with sush contractor. 
CONTENTS

Page

Introduction ........................ 5 Boiling as Applied to Liquid Metals . . . . . . . . . . . 20 Behavior of Natural- and Forced-Circulation Loops . . . . . . 24 Forced-Convection Heat Transfer . . . . . . . . . . . . 27 Cavity Size Calculations. . . . . . . . . . . . . . . 32

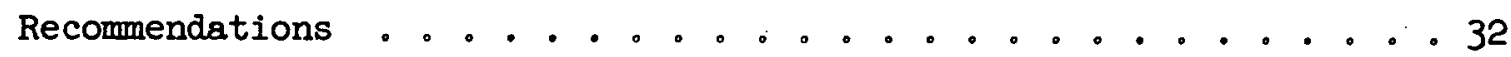
References ..................... 34 
THIS PAGE

\section{WAS INTENTIONALLY \\ LEFT BLANK}


NOTES ON THE LIQUID-METAL BOILING PHENOMENON

A. I. Krakoviak

INTRODUCTION

A brief review of the boiling phenomenon in ordinary fluids (water, alcohol, etc.) with emphasis on the superheat required to initiate a bubble from a surface may be useful in explaining the erratic behavior observed in the natural-and forced-circulation boiling-potassium loops at the Oak Ridge National Iaboratory.

The characteristic boiling curve similar to the one shown in Fig. 1 was first developed by Nukiyama ${ }^{2}$ in 1934, who boiled water from an electrically heated horizontal platinum wire submerged in a pool of water at saturation temperature. In boiling regime $I$, as the wall temperature is raised above saturation temperature, convection currents circulate superheated liquid and vapor is produced by evaporation at the free liquid surface. In regime II, a further increase in wall temperature results in the formation of vapor bubbles which rise from favored spots on the heated surface and condense before reaching the free surface. In regime III, more numerous bubbles form at the heated surface and rise to the free liquid surface and into the vapor space. This article will be limited to these three regimes.

Heidrich ${ }^{2}$ in 1931, using distilled degassed water in a clean glass container heated by a solution of calcium chloride, investigated the temperature distribution and heat flow rates for regime $I$ where vapor is produced by evaporation from the free liquid surface without the formation of bubbles at the heated surface. The curves in Fig. 2 show that near the surface the temperature gradient is linear, indicating a stagnant layer through which heat is transferred by conduction alone. At the higher values of liquid superheat, larger temperature gradients through thinner stagnant layers accompanied higher evaporation rates, w/A. Below the stagnant layer, convection currents tend to maintain a constant temperature with depth。 


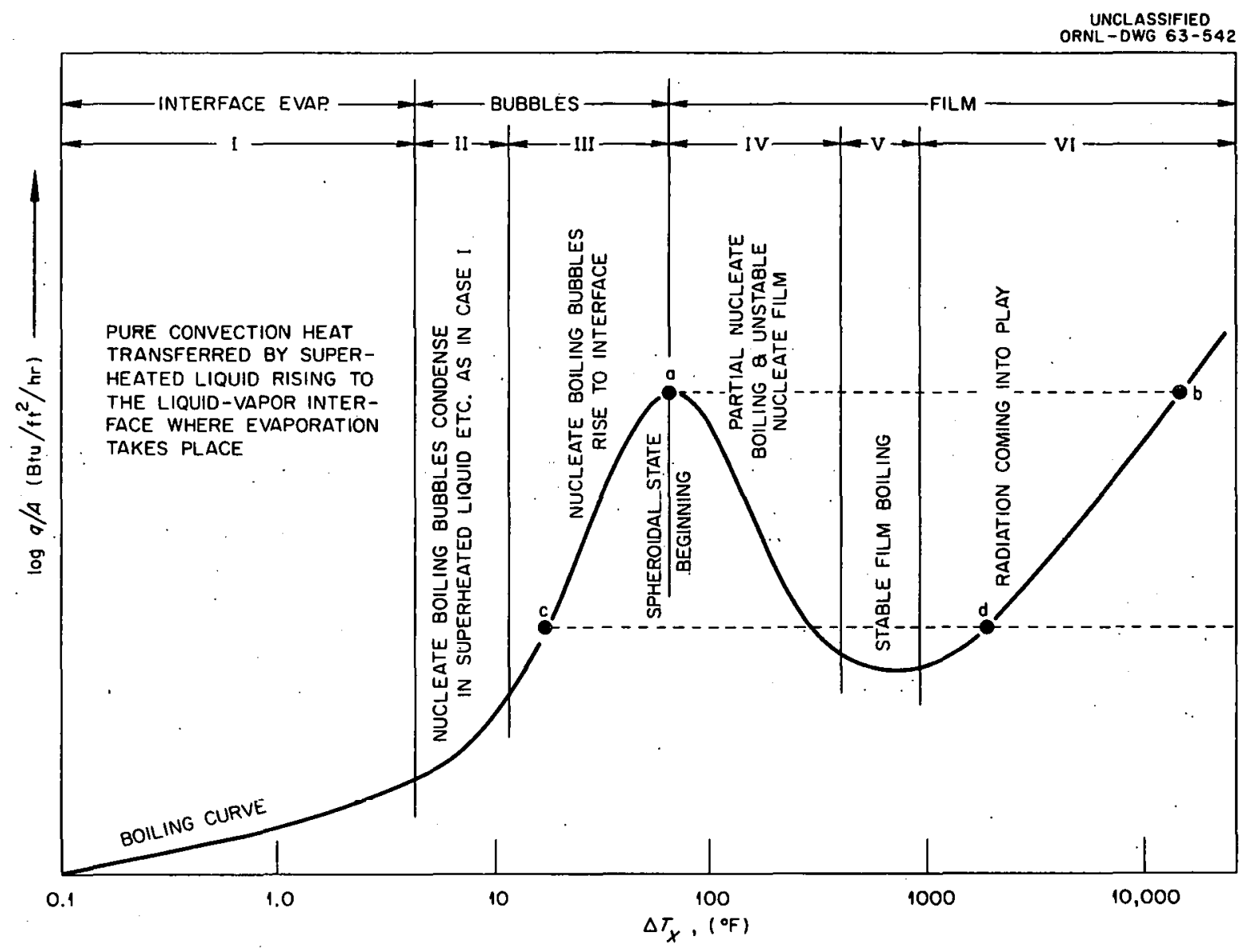

T.ig. 1. Typical Boiling Curve for Water. 


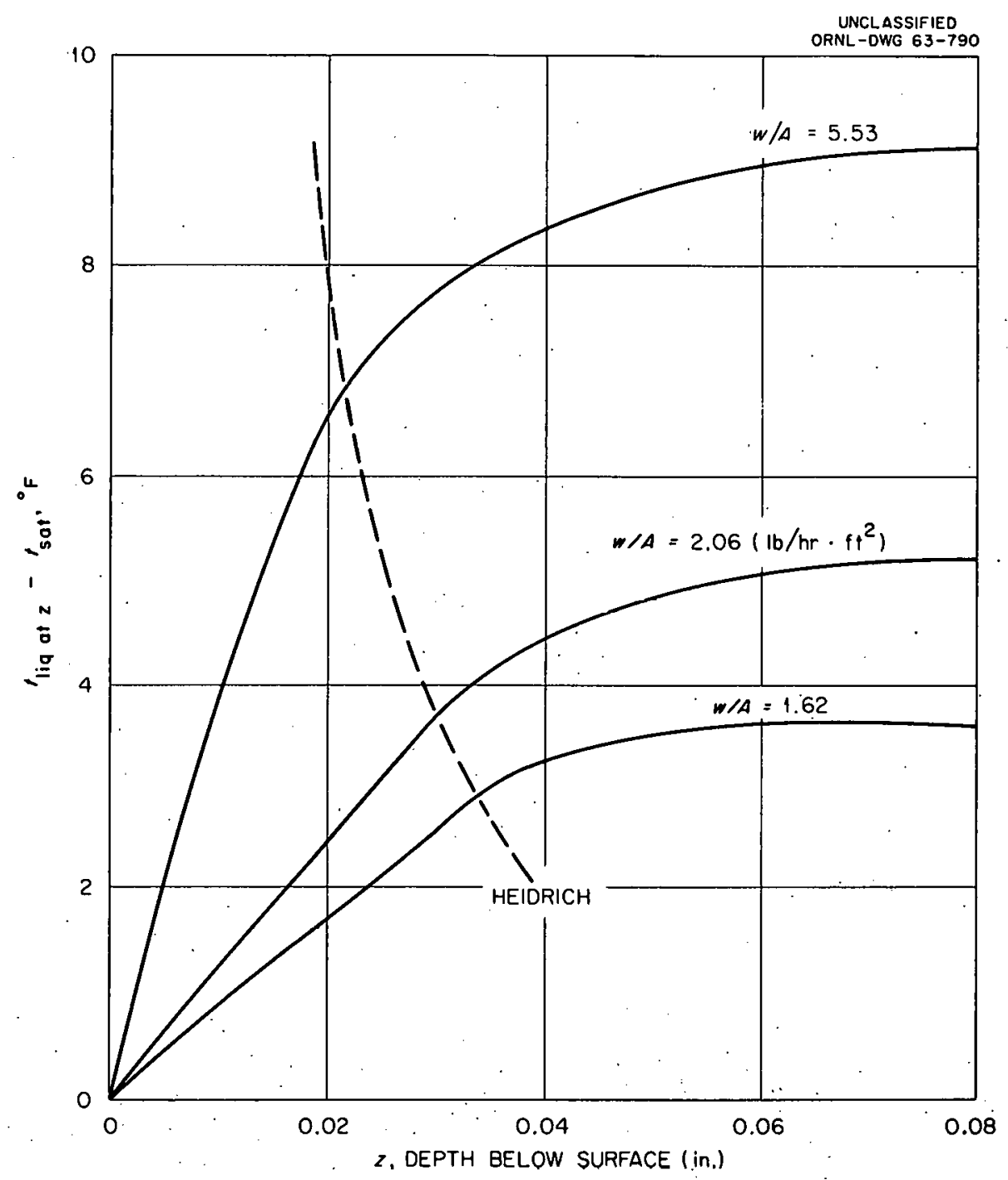

Fig. 2. Liquid Superheat as a Function of Depth and Boiling Rate in a Pool of Water. 
In regimes II and III (where vapor bubbles are formed), the Laplace equation relates the pressure, $P_{v}$, of a vapor inside a spherical bubble and the external pressure on the liquid, $P_{\ell}$, to the radius of the bubble, $r$, and the surface tension of the liquid, $\sigma$, as follows:

$$
\mathrm{P}_{\mathrm{v}}-\mathrm{P}_{\ell}=\frac{2 \sigma}{\mathrm{r}} \text {. }
$$

This equation shows that for bubble growth, $\mathrm{P}_{\mathrm{v}}$ must be greater than $\mathrm{P}_{\ell}$, and for evaporation the temperature of the liquid must be greater than the temperature of the vapor; thus for boiling to exist, the liquid must be superheated with respect to the vapor in the bubble as well as to itself.

Ellion ${ }^{3}$ in 1954 combined the Clausius-Clapeyron equation with the equation of Laplace for a thermodynamic evaluation of the nucleation process with the following equation by assuming the specific volume of the vapor is large compared with that of the liquid and that it can be found by the gas law, $V_{g}=\left(R_{\text {sat }}\right) / P_{\ell}$ :

$$
T_{v}-T_{\text {sat }}=\frac{2 R T_{\text {sat }}^{2} \sigma}{h_{f g} P_{\ell} r} \text {, }
$$

where

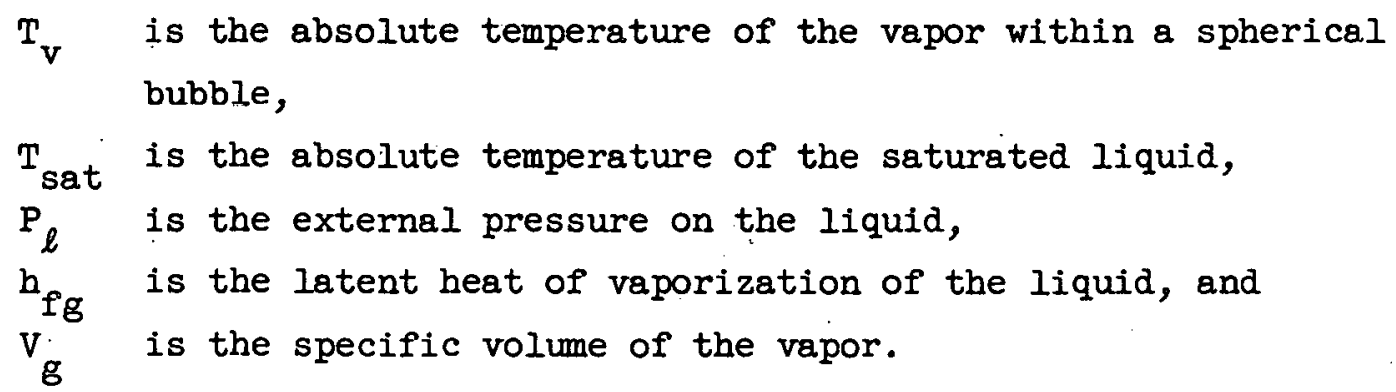
This equation predicts the approximate liquid superheat required for equilibrium of a bubble of radius $r$.

Wallis and Griffith in 1959 carried out nucleation experiments by immersing in watèr a cópper sheet containing a conical cavity made by pressing into the surface of the copper a phonograph needle having an apex angle of $18^{\circ}$. Using the cavity radius at its mouth as $r$, their 
data agreed quite well with Eq. (2) as shown in Fig. 3. They showed that the superheat required to maintain ebullition at a rate from 0.2 to 5 bubbles/sec was inversely proportional to pressure.

Berenson ${ }^{5}$ using a heated copper surface showed that higher wall superheats were required at a given heat flux to boil pentane from smoother surfaces. The curves in Fig. 4, from left to right, represent the wall superheats required for surfaces which had been finished with progressively finer emery cloth. The smoother surface has smaller cavities and hence the radius of curvature of the vapor bubble is smaller than for the rough surface and from Eq. (2) requires a greater wall superheat for bubble growth.

Farber and $\mathrm{Scorah}^{\mathbf{6}}$ using Chromel $\mathrm{C}$ wire submerged in water showed that a smaller wall superheat at a given heat flux is required for boiling as pressure is increased. Their data in Fig. 5 are also consistent with Eq. (2).

From a photographic study of the velocities and paths of bubbles in pool boiling experiments, Jakob ${ }^{7}$ noticed that bubbles appeared to initiate at favored spots on the heated surface and that the frequency of bubble formation depends on the size of the bubbles at the moment of break-off. His data in Fig. 6 show frequency to be a hyperbolic function of the diameter of a sphere having the same volume as the bubble at the moment of break-off. He also observed that in the heat flux range up to $18,000 \mathrm{Btu} / \mathrm{hr} \cdot \mathrm{ft}^{2}$ an increase of $700 \mathrm{Btu} / \mathrm{hr}^{2} \mathrm{ft}^{2}$ activated one more cavity to produce a steam column.

Any surface has a cavity size distribution peculiar to that particular surface and may be represented by the curve in Fig. 7. As heat is applied to the surface, the larger cavities become activated first, and as heat flux is increased more cavities and hence smaller cavities become activated requiring greater wall superheats in accordance with Eq. (2). Rohsenow ${ }^{B}$ postulates that the slope of the $q / A$ vs $\Delta T$ curve expresses the change in $\Delta T$ necessary to increase the number of activated cavities sufficiently to accommodate the new heat flux. Although the slope is predominantly in the neighborhood of three, data are available showing slopes varying from unity for contaminated surfaces to slopes 


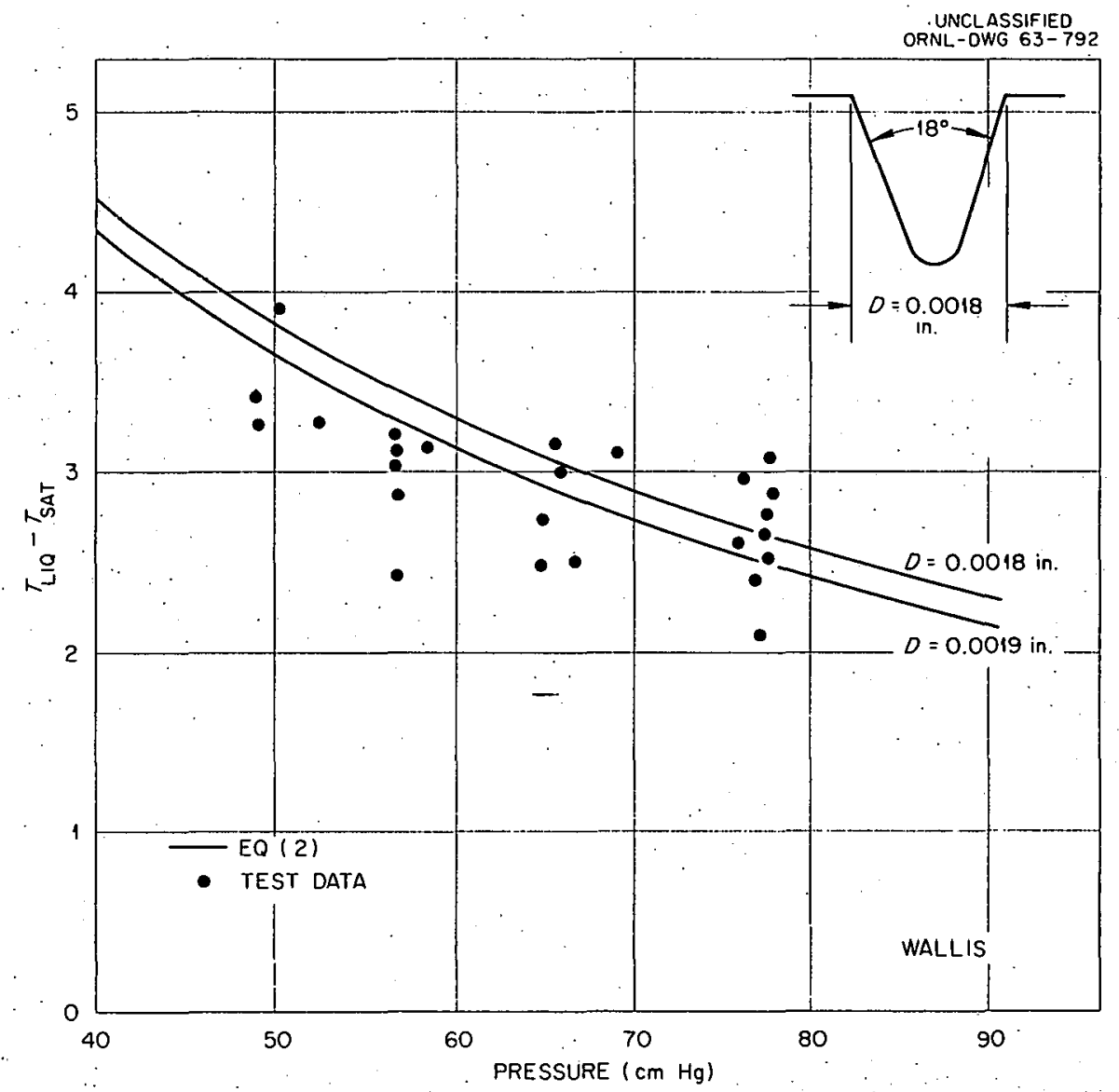

Fig. 3. Measured Superheat Compared with Those Calculated. 


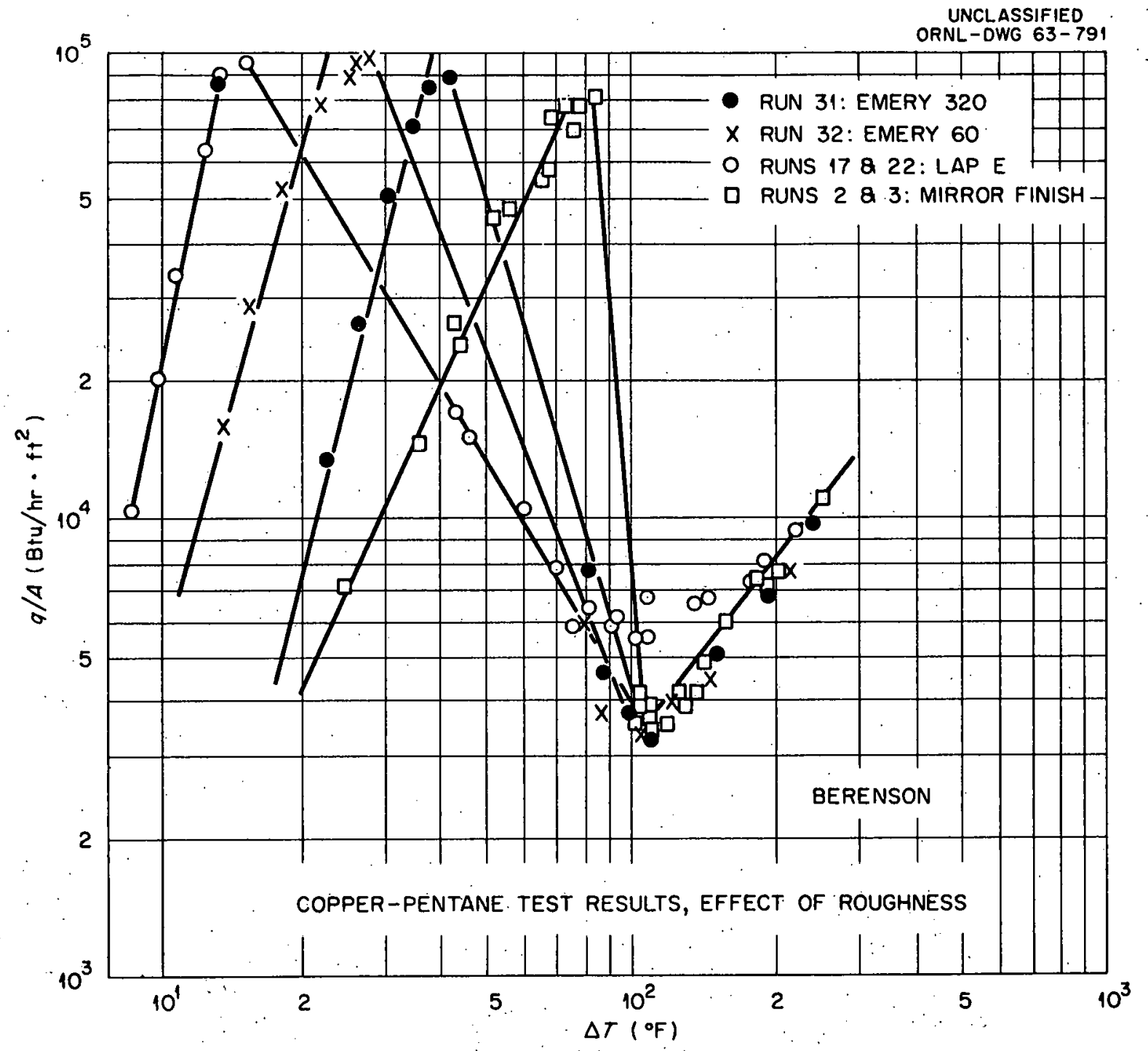

Fig. 4. Effect of Surface Roughness on Superheat. 


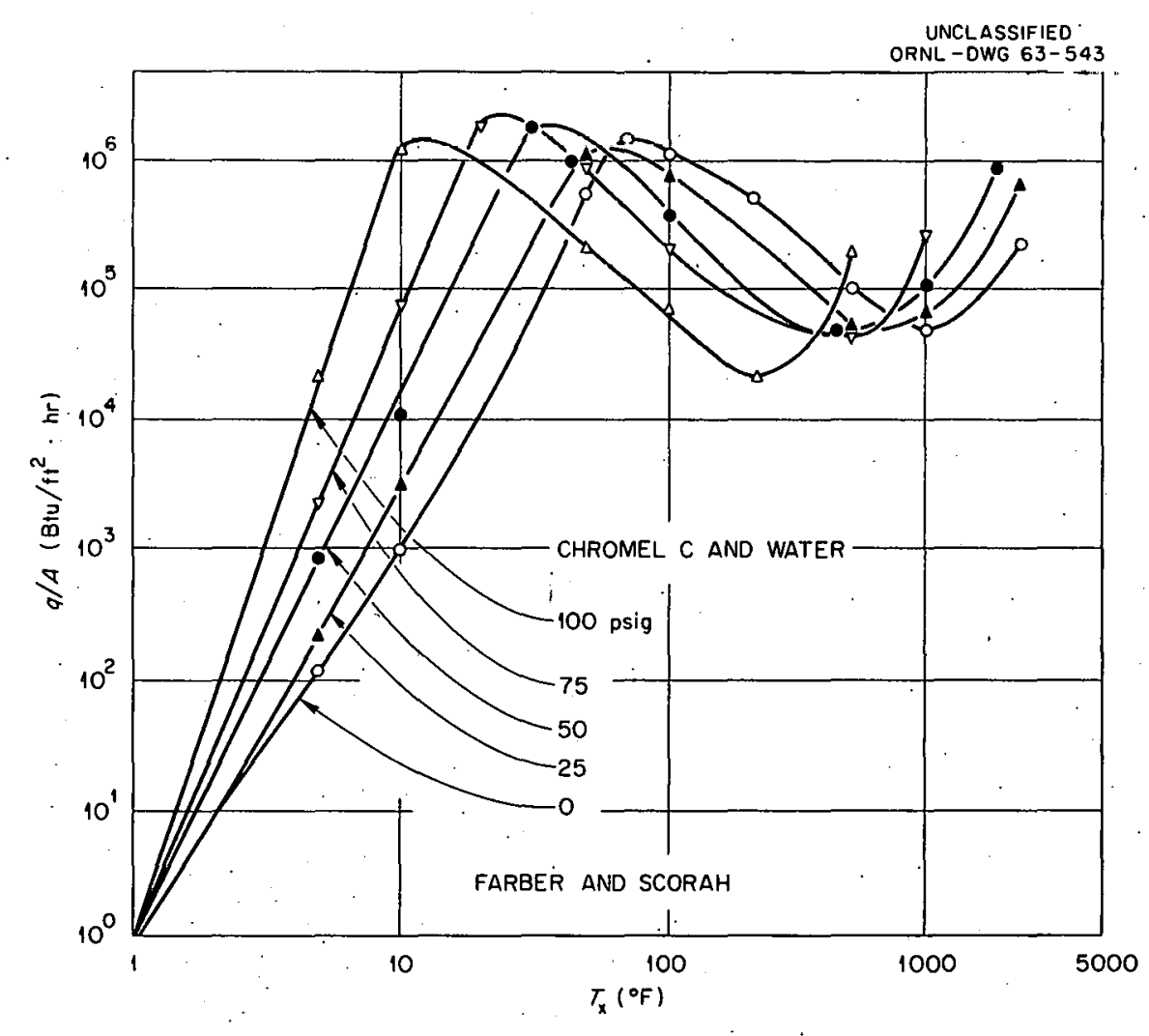

Fig. 5. Effect of Pressure on Superheat. 


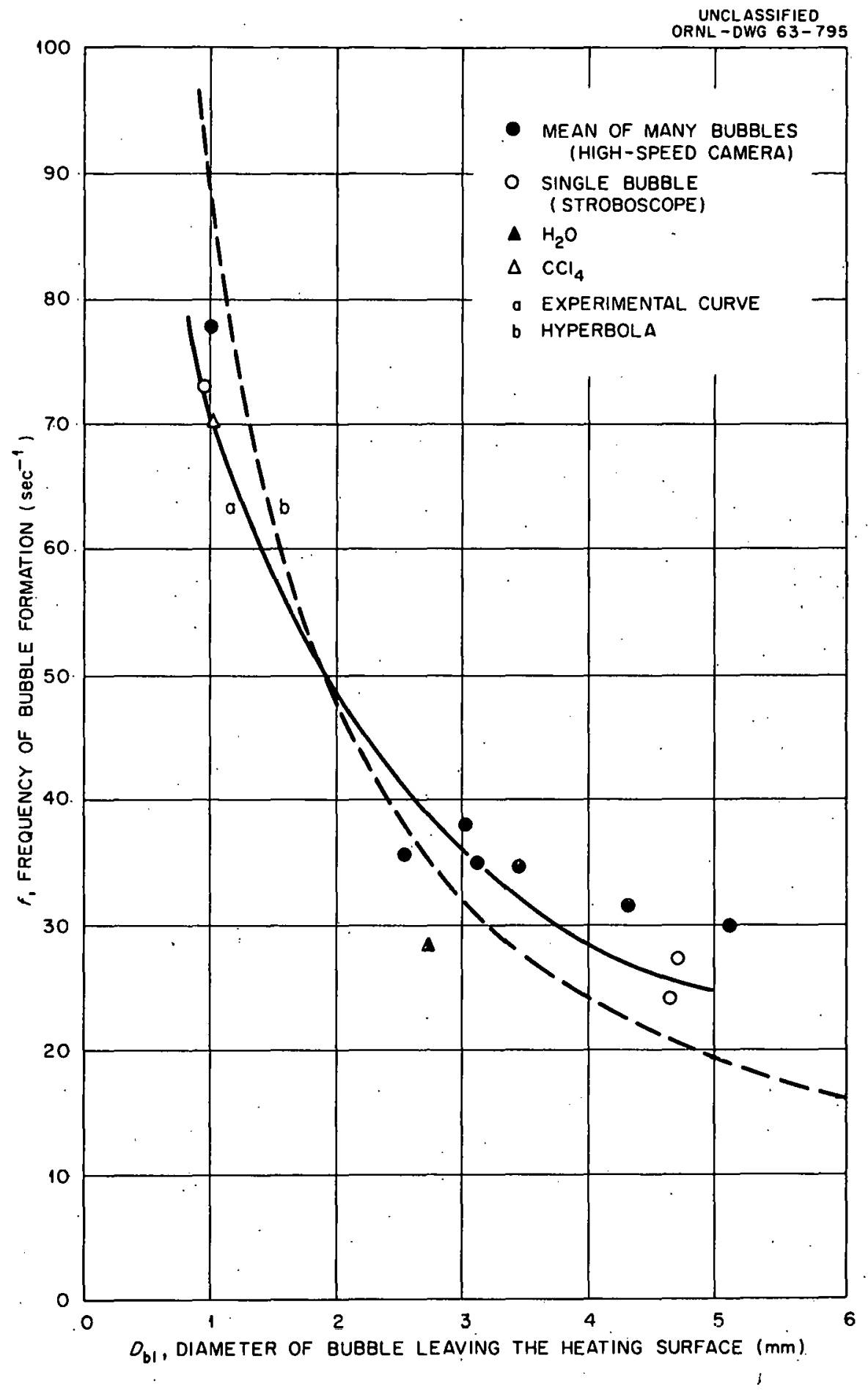

Fig. 6. Bubble Formation Frequency as a Function of Bubble. Diameter. 


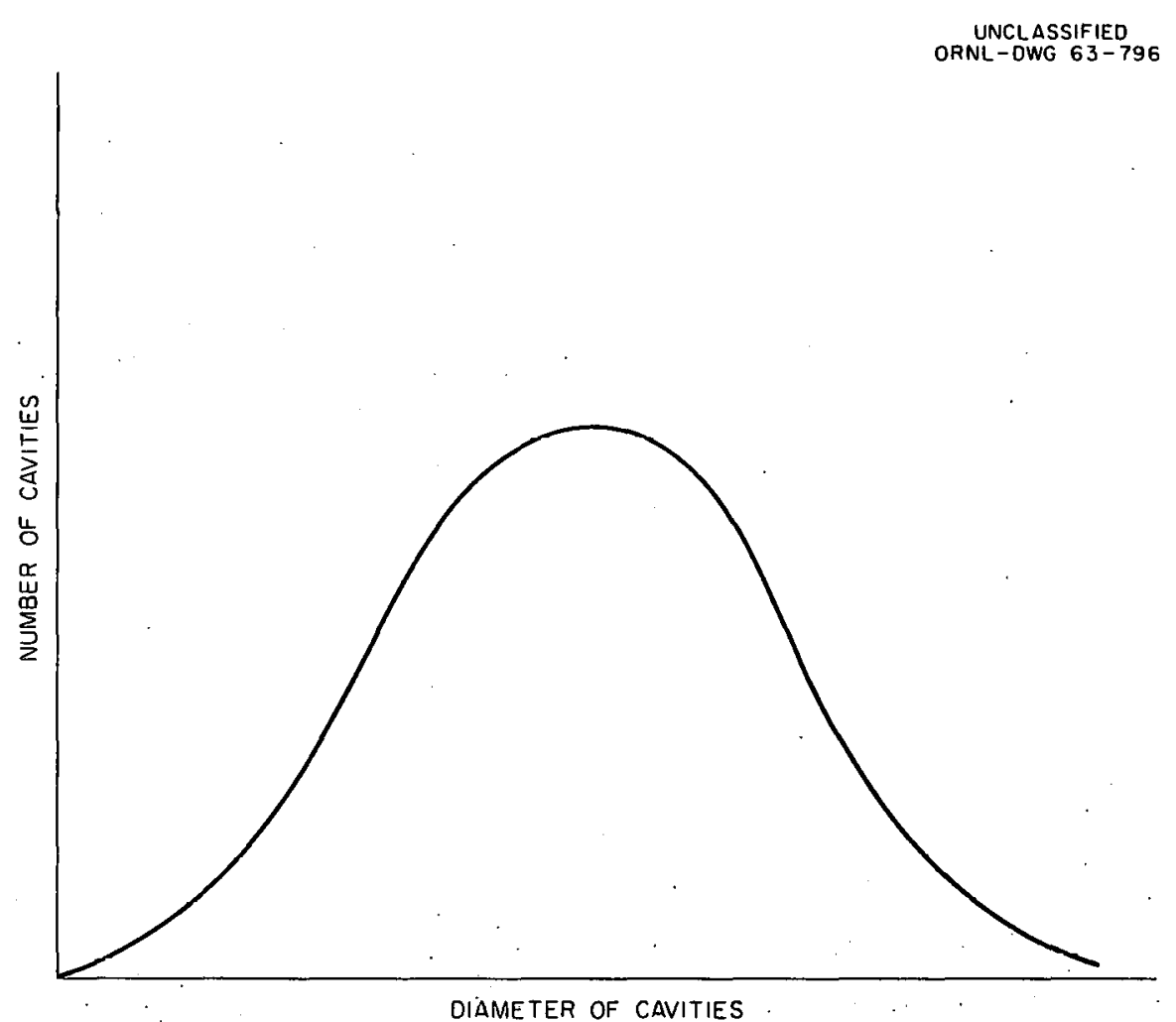

Fig. 7. Normal Cavity Size Distribution Curve. 
of 25 for very clean surfaces. It is his postulate that the actual slope depends upon the uniformity of the size and shape distribution of the cavities in a particular surface.

Wallis and Griffith ${ }^{4}$ have counted nucleation spots as a function of wall superheat for three different fluids (ethanol, methanol, and water) boiling from the same surface and obtained the curves shown in Fig. 8 . Rearranging Eq. (2) and applying the ideal gas law equation, they presented Eq. (2) in the following form:

$$
r=\frac{2 \sigma T_{w} V_{f g}}{h_{f g}\left(T_{w}-T_{s a t}\right)}
$$

where

$V_{f g}$ is the specific volume change of vaporization, and
$T_{w}$ is the absolute temperature of the wall. Using the observed superheat values from Fig. 8 in Eq. (3), the calculated cavity radius, $r$, produced one line common to the three fluids as shown in Fig. 9, thus characterizing that particular surface for boiling heat transfer.

Corty and Foust ${ }^{9}$ reported a hysteresis loop for the $q / A$ vs $\Delta T$ plot as shown in Fig. 10. When a particular surface is immersed in a liquid and as heat is applied to the surface, the boiling curve may trace any line between abdc and abfc to point $C$, depending on the amount of inert gas trapped in the cavities of the surface. When the heat flux is reduced after having boiled at point $\mathrm{C}$ for quite some time, the boiling curve follows the path cdba where boiling ceases. A subsequent increase in heat flux may cause the boiling curve to follow the path abe before boiling is initiated and returns to point C. Griffith and Wallis reported that a surface which produced a boiling curve following path abgc with tap water would follow curve abedc if the water was degassed before starting. Apparently, the degassed water dissolved all of the gas from the cavity before boiling began; consequently, the cavity filled with liquid and was no longer active. ${ }^{4}$ These investigators also showed that conical cavities such as shown in Fig. lla are not stable, whereas the 


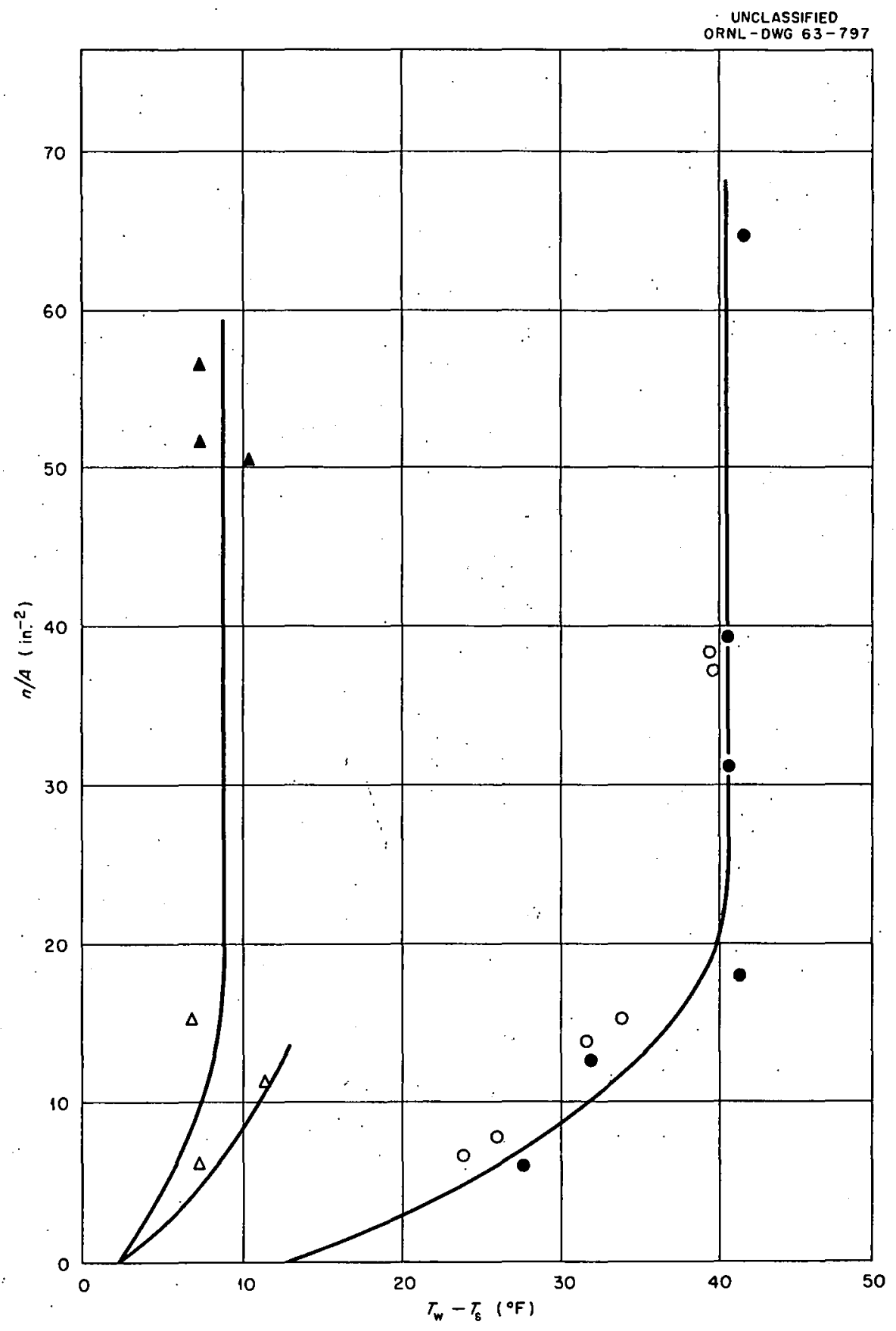

Fig. 8. Number of Active Spots per Unit Area Vs Wall Superheat. 


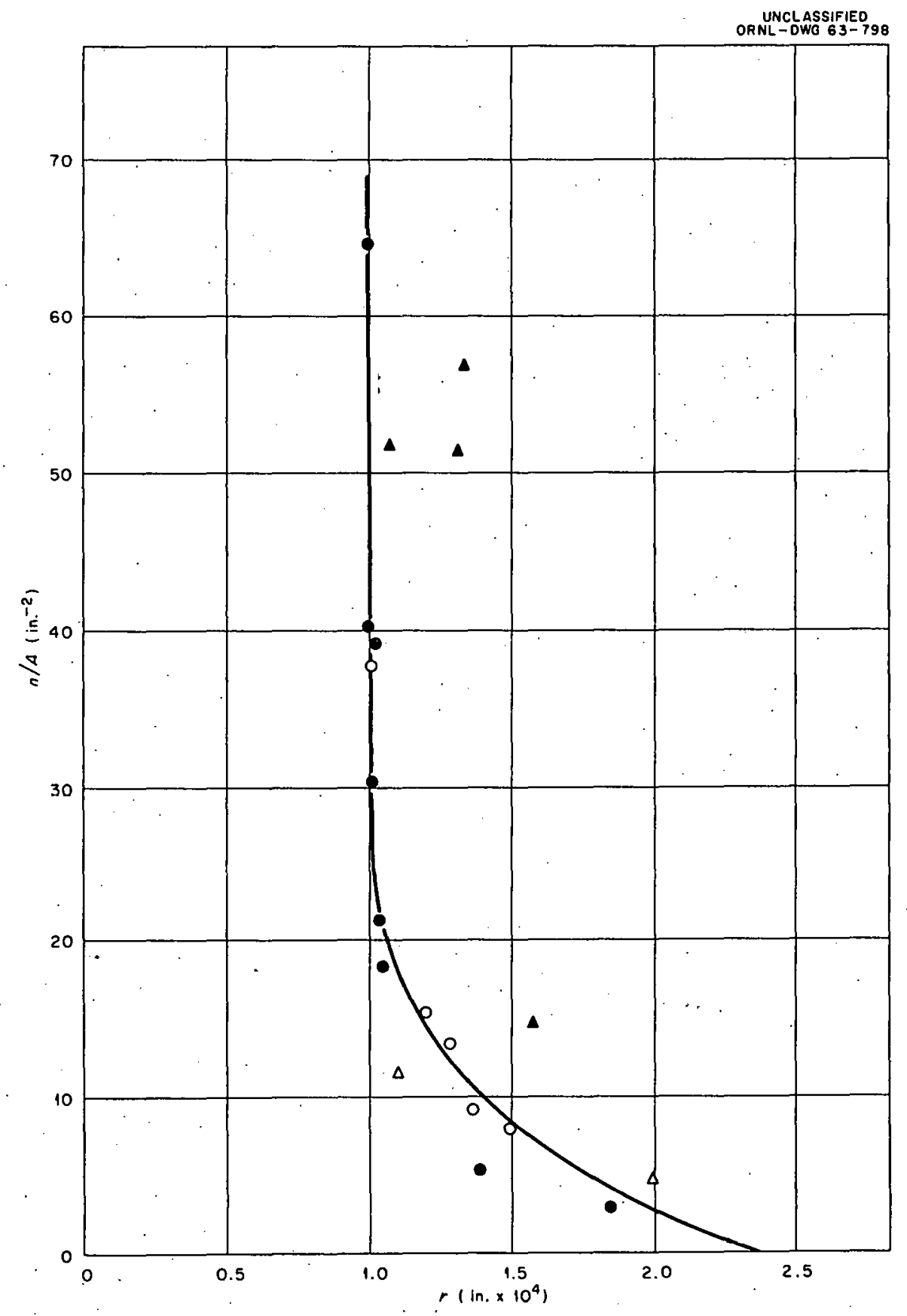

Tig. 9. Data From Fig. 8 as a Function of $r$ as Calculated from Eq. (3). 


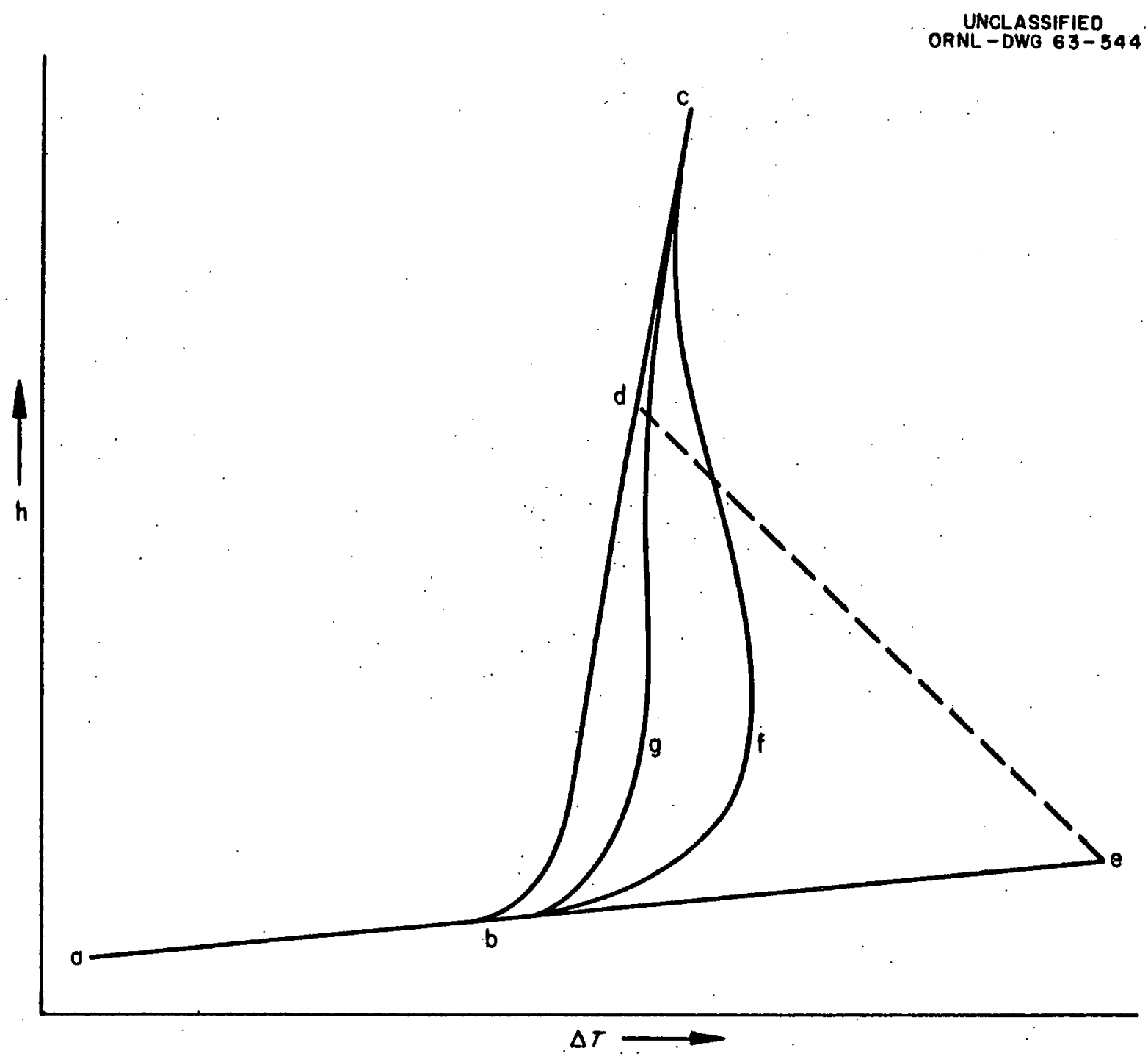

Fig. 10. Typical Hysteresis Loop for Pool Boiling of Water. 


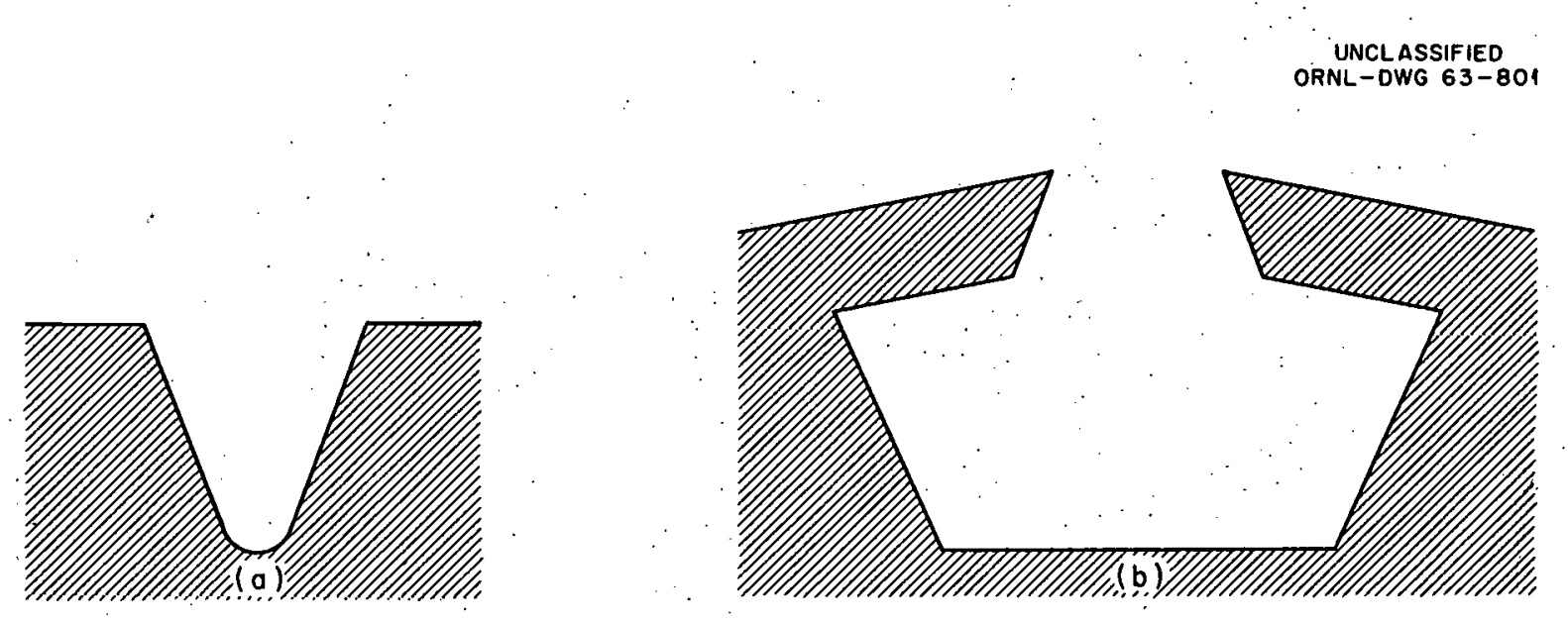

Fig. 11. Conical and Re-entrant-Type Cavities. 
re-entrant-type cavities shown in Fig. Ilb are very stable in that the liquid must be subcooled to deactivate this type of cavity. Wallis and Griffith also reported that a sudden increase in pressure during boiling would deactivate a cavity and cause the boiling curve to follow path abed in Fig. 10 before boiling could be re-established.

\section{BOILING AS APPLIED TO LIQUID METALS}

Since Eq. (2) is substantiated by the experimental data of several investigators working with more than one fluid, one may calculate, by . comparison with water, the superheat required to initiate a vapor bubble. from a surface immersed in a liquid metal with the following equation:

$$
\frac{T_{v_{w}}-T_{\text {sat }}}{T_{v_{x}}-T_{\text {sat }}}=\frac{\sigma_{w} T_{v_{w}} V_{f g_{w}} h_{f g_{x}} r_{x}}{\sigma_{x} T_{v_{x}} \cdot v_{f g_{x}} h_{f g_{w}} r_{w}},
$$

where the subscripts $w$ and $x$ refer to water and a liquid metal, respectively.

Using the physical properties (Table l) of water, sodium, potassium, rubidium, and cesium at their respective normal boiling points and assuming that $30^{\circ} \mathrm{F}$ is required to sustain vapor bubbles from a particular surface with a cavity of radius $r$ immersed in water at atmospheric pressure, the superheats required to sustain vapor. bubbles from the same surface immersed in the above alkali metals (at one atmosphere) were calculated. It was found that superheats of $30,125,258,10 i$, and $67^{\circ} \mathrm{F}$ were required to sustain vapor bubbles from a given cavity when in $\mathrm{H}_{2} \mathrm{O}$, $\mathrm{K}, \mathrm{Na}, \mathrm{Rb}$, and $\mathrm{Cs}$, respectively. In comparison with water, this means that the superheat required to initiate bubble formation must be increased by a factor of 4.2 for $\mathrm{K}, 8.6$ for $\mathrm{Na}, 3.4$ for $\mathrm{Rb}$, and 2.2 for $\mathrm{Cs}$. The boiling potassium loops of interest are those boiling in the absence of inert gases. These then should be compared with distilled, degassed water boiling from a clean surface, where superheats of $\sim 90^{\circ} \mathrm{F}$ are required to initiate a vapor bubble as was discussed for the hysteresis loop in Fig. 10. Comparable superheats calculated to initiate vapor bubbles in $\mathrm{K}, \mathrm{Na}$, $\mathrm{Rb}$, and $\mathrm{Cs}$ at atmospheric pressure are then $375,774,203$, and $201^{\circ} \mathrm{F}$, 
Table 1. Physical Properties of Water and Liquid Metals Evaluated at their Respective Normal Boiling Points

\begin{tabular}{|c|c|c|c|c|c|c|}
\hline Liquid & $\begin{array}{l}\text { Normal Boil- } \\
\text { ing Point, } \\
{ }^{\circ} \mathrm{F}\end{array}$ & $\begin{array}{l}\text { Spec. Vol, } \\
\text { Vapor } \\
\mathrm{ft}^{3} / \mathrm{lb}\end{array}$ & $\begin{array}{l}\text { Density } \\
\text { of Liquid, } \\
\text { lb/ft }\end{array}$ & $\begin{array}{c}\text { Latent Heat of } \\
\text { Vaporization, } \\
\text { Btu/lb }\end{array}$ & $\begin{array}{l}\text { Thermal } \\
\text { Conductivity, } \\
\text { Btu/hr } \cdot \mathrm{ft} \cdot{ }^{\circ} \mathrm{F}\end{array}$ & $\begin{array}{l}\text { Surface } \\
\text { Tension, } \\
\text { lb/ft }\end{array}$ \\
\hline Water. & 212 & 26.80 & 59.83 & 970 & 0.393 & 0.00403 \\
\hline Potassium & 1400 & 32.47 & 41.58 & 851 & 18.1 & $0.0043^{a}$ \\
\hline Sodium & 1618 & 60.6 & 46.4 & 1609 & 30.1 & $0.0077^{b}$ \\
\hline Rubidium & 1270 & 16.67 & 82.15 & 347.5 & 11.8 & $0.003^{c}$ \\
\hline Cesium & 1260 & 10.42 & 104.7 & 213.8 & 10.6 & $0.002^{c}$ \\
\hline
\end{tabular}

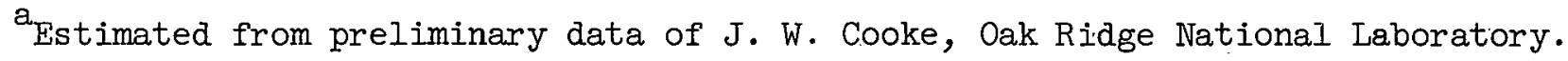

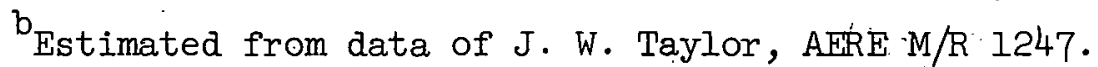

Estimated from data of S. W. Strauss, "Surface Tension of Liquid Metals at their Melting Points," Nuclear Science and Engineering, 8: 362-363 (1960). 
respectively.

The foregoing assumptions and calculations coupled with the high thermal conductivity of potassium may explain the observed boiling instabilities and anomalies in the natural- and forced-circulation loops at ORNL. In the forced-circulation loop operated by the author (when potassium entered the boiler subcooled), wall temperatures on the boiler increased relatively slowly ( $20 \mathrm{sec}$ ) to approximately 150 to $250^{\circ} \mathrm{F}$ above the average operating temperature. At this temperature (not necessarily constant), there was an extremely rapid $\left(10^{-1} \mathrm{sec}\right)$ decrease in boiler temperature with a simultaneous and equally rapid increase in loop pressure and condenser temperature.

To illustrate the widely different temperature profiles and thus the different boiling behavior between water and liquid metals, imagine an infinitely long l-in.-OD solid rod surrounded by an infinitely long clamshell-type heater. After a sufficient length of time with energy radiating to the rod at a constant rate of, say, $30,000 \mathrm{Btu} / \mathrm{hr} \circ \mathrm{ft}^{2}$ (maximum heat flux of all but one boiling-potassium loop at ORNL), the temperature profile within the rod will assume the paraboloid of revolution shown in Fig. 12a. Paths $a$ and $b$ represent the temperature gradients in a rod of thermal conductivities equivalent to potassium $\left(18.1 \mathrm{Btu} / \mathrm{hr} \cdot \mathrm{ft} \cdot{ }^{\circ} \mathrm{F}\right.$ ) and water (0.393), respectively. Now if this rod is replaced with a 1-in.ID tube filled with water with 1 atm of pressure above it, then when the wall temperature rises to $30^{\circ} \mathrm{F}$ (depending on the cavity size of heated surface) above.saturation temperature, tiny "explosions" of liquid into vapor take place at the wall and grow very rapidly in the $0.005-i n$. superheated annulus depicted in Fig. $12 b$ before moving toward the center of the tube where they either grow more slowly or collapse, depending on whether the fluid is at saturation temperature or subcooled. If subcooled, the fluid would eventually reach saturation temperature and remain there with $T_{W}$ $\sim 30^{\circ} \mathrm{F}$ higher than saturation temperature and boil with no great pressure perturbations. Now if this rod is replaced with a l-in.-ID tube filled with potassium with 1 atm of pressure above the potassium, then the wall temperature would rise $375^{\circ} \mathrm{F}$ above saturation temperature before bubble nucleation at the wall. However, because of the conductivity of potassium, 


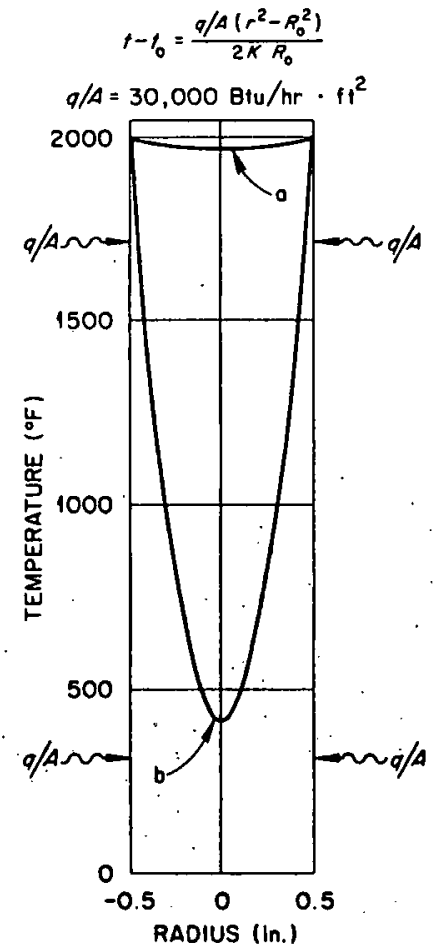

(a)

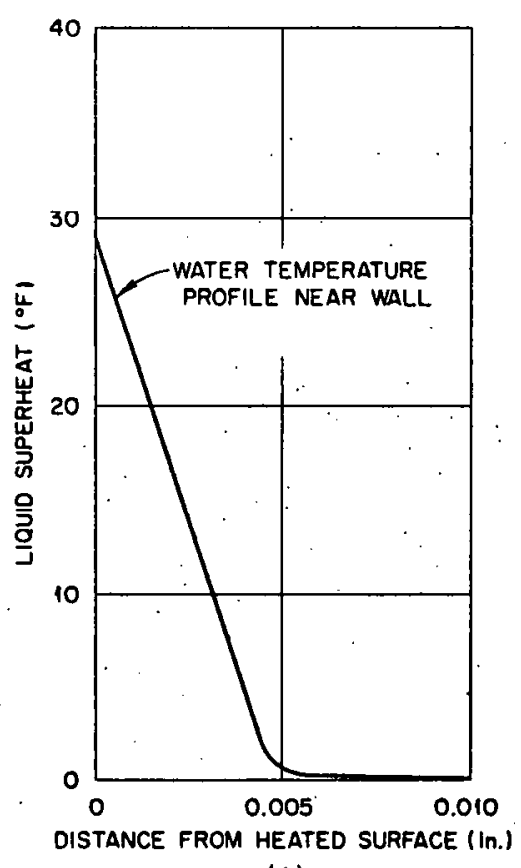

(o)

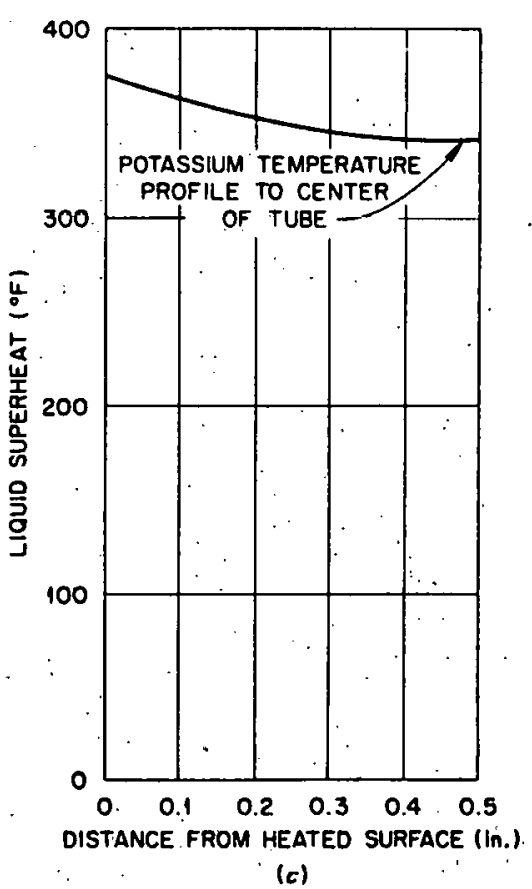

(c)

Fig. 12. Temperature Profile Within a Rod Under Conditions Discussed on Page 22. 
the entire volume of potassium in the tube would be at a superheat of not less than $340^{\circ} \mathrm{F}$ (Fig, 12c). Now when a bubble nucleates, the energy of superheat from the entire volume is released in a matter of microseconds in a violent "explosion". The energy of superheat in a unit volume of potassium when released under these conditions produces a vapor quality of $\approx 7.6$ wt $\%$, resulting in a momentary high-pressure surge and supplies a large amount of vapor to the condenser, thus increasing the condenser temperatures. This cycle repeats itself at a frequency depending on the heat flux and thermal gradient in the bubble producing cavity. If the heated surface contains a rementrant-type cavity with a sufficiently high thermal gradient to maintain a liquid-vapor interface at the cavity mouth, then stable boiling without excessive liquid superheat can be expected.

If Eq. (2) is used to calculate the superheat required to initiate a bubble from a surface (a surface which requires a superheat of $30^{\circ} \mathrm{F}$ to maintain a steam bubble) and Fourier's conduction equation is used to calculate the heat transfer across a liquid (assuming no convection contribution), the curves in Fig. 13 indicate that a 2.5 in. thickness of sodium at $1618^{\circ} \mathrm{F}$ will sustain a heat flux of $1 \times 10^{5} \mathrm{Btu} / \mathrm{hr} \circ \mathrm{ft}^{2}$ without nucleating a vapor bubble at the heated surface; the same thickness of potassium will sustain a heat flux of $3.3 \times 10^{4} \mathrm{Btu} / \mathrm{hr}^{\mathrm{ft}} \mathrm{ft}^{2}$ without nucleation. Increased pressure at the heated wall due to static liquid head and convection currents (neither of which were considered in this analysis) would increase the sustainable heat flux appreciably。 ${ }^{10}$ Consequently, all liquid-metal pool bolling data ( $q / A$ vs $\Delta T$ ) taken without the aid of a contact microphone or other means to detect ebullition should be questioned.

\section{BEHAVIOR OF NATURAL- AND FORCED-CIRCULATION IOOPS}

In the case of natural-circulation loops of the closed Uatube manometer type, nucleation and concomitant release of the energy of superheat (evidenced by a pressure surge and boiler temperature decay) take place in a matter of microseconds, whereas the temperature increase or superheat buildup portion of the cycle takes 20 to $60 \mathrm{sec}$, depending on heat flux and heat capacity of the fluid and boiler. During this temperature 


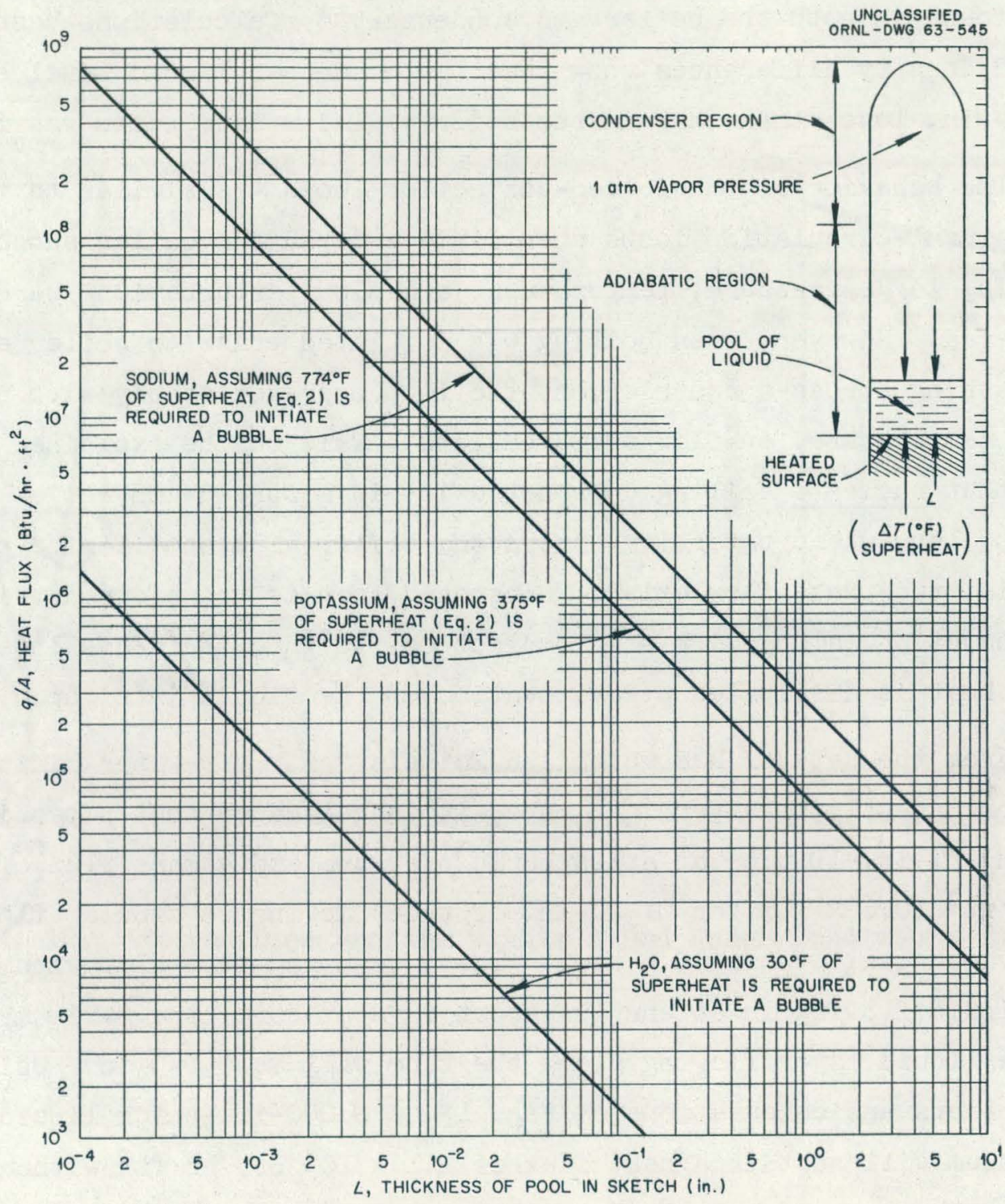

Fig. 13. Heat Conduction as a Function of $\Delta t$ and Thickness. 
buildup portion of the cycle, the liquid level in the boiler and condenser does not fluctuate, and vapor is produced only by evaporation at the liquid-gas interface in the boiler. This is supported by the fact that sharplines of demarcation (delineating the liquid-vapor interfaces) were found in both the boiler and condenser. ${ }^{11}$ Calculations based on liquid density differences show that the condenser liquid level should be $\sim 1$ 1/4 in. lower than that in the boiler; 1 -in. difference was found.

The behavior of the forced-convection loops was similar to that in the natural-circulation loops when fluid entered the boiler subcooled; that is, large pressure, temperature, and flow perturbations were encountered. However, when boiling was initiated prior to boiler entrance by flashing across a restriction, the loop operated stably with no pressure, temperature, or flow perturbations. This can be explained by the fact that nucleate boiling does not exist in a forced-convection potassium boiler, where potassium enters the boiler with some finite quality; that is, two-phase flow exists. Instead, heat is transferred primarily by conduction (along with some convection) to the liquid-gas interface where heat is dissipated by evaporation of the liquid into vapor.

From the data of Radovcich and Moissis ${ }^{12}$ for air-water mixtures flowing concurrently in a vertical tube, it is estimated that potassium flowing in a 1 -in.-ID tube at atmospheric pressure and a mass flux of $1 \times 10^{5}$ $1 \mathrm{~b} / \mathrm{hr} \cdot \mathrm{ft}^{2}\left(0.6 \times 10^{5}\right.$ for $0.320-\mathrm{in}$. -ID tube $)$ is in the annular flow regime at a vapor quality of $\geq 0.4$ wt $\%$. Then, assuming zero slip with all of the liquid flowing in an annulus about a vapor core, the maximum thickness of the liquid layer flowing along the tube wall is $0.040 \mathrm{in}$. Using the assumptions and calculations of Fig. 13, a 0.040-in.-thick liquid film of potassium will sustain a heat flux of $2.1 \times 10^{6} \mathrm{Btu} / \mathrm{hr} \cdot \mathrm{ft}^{2}$ without nucleation at the heated surface $\left(7 \times 10^{6}\right.$ for sodium). Thus nucleate boiling is "suppressed" because the high thermal conductivity of the annulus of liquid potassium and vaporization at the liquid-gas interface preclude the development of sufficient wall superheat to initiate bubble formation at the liquid-solid interface. 
Dengler and Addoms, ${ }^{13}$ working with a water system heated by steam jackets, have reported forced-convection nucleate boiling at low qualities in the first half of their boiler and forced-convection surface evaporation in the latter half of their boiler where high qualities and very thin liquid annuli existed. Their forced-convection nucleate boiling data are presented as the solid dots in Fig. 14.

Schrock and Grossman ${ }^{24}$ in 1961, working with water in forcedconvection electrically heated test sections, correlated their results to both the Lockhart-Martinelli two-phase flow parameter, $\mathrm{x}_{t t}$, and to a boiling number, $B_{0}$, first described by Mumm. ${ }^{15}$ The boiling number, $B_{0}=$ $(\mathrm{q} / \mathrm{A}) / \mathrm{G} \mathrm{h}_{\mathrm{fg}}$, is the ratio of radial heat flux to longitudinal heat flow. In Fig. 15 they point out that heat-transfer coefficients with high boiling numbers (where nucleate boiling predominates) are independent of the Lockhart-Martinelli parameter, whereas for the case of low boiling numbers (where nucleate boiling is precluded and surface evaporation takes place), the heat-transfer coefficients are strongly dependent on the two-phase parameter. They correlated all of their data with $B_{0}$ and $x_{t t}$ as shown in Fig. 16.

A Dengler-Addoms type of correlation is shown in Fig. 17 for potas sium where $\mathrm{h} / \mathrm{h}_{l}$ is the ratio of the heat-transfer coefficient with boiling (h) to that which would be obtained without boiling $\left(h_{\ell}\right)$ at the same inlet mass flow and is a measure of the improvement in heat transfer which aco crues from the boiling process. For the low flows of this investigation (Peclet moduli < 100), the nonboiling coefficient was based on the equation $\mathrm{N}_{\mathrm{Nu}}=0.047 \mathrm{~N}_{\mathrm{Pe}}$, as developed from the data of Johnson, Hartnett, and Cla. baugh $^{16}$ and from preliminary results with potassium at ORNL. The runs are grouped in series of three to five runs; there were equipment repairs and delays between series. Although there is wide scatter in the data, the slope of each series is consistent with each of the others and to that for water. The scatter among series is attributable to a faulty thermocouple controlling the adiabatic region near the boiler exit thermocouple well. This was noticed after the boiler was disassembled. 


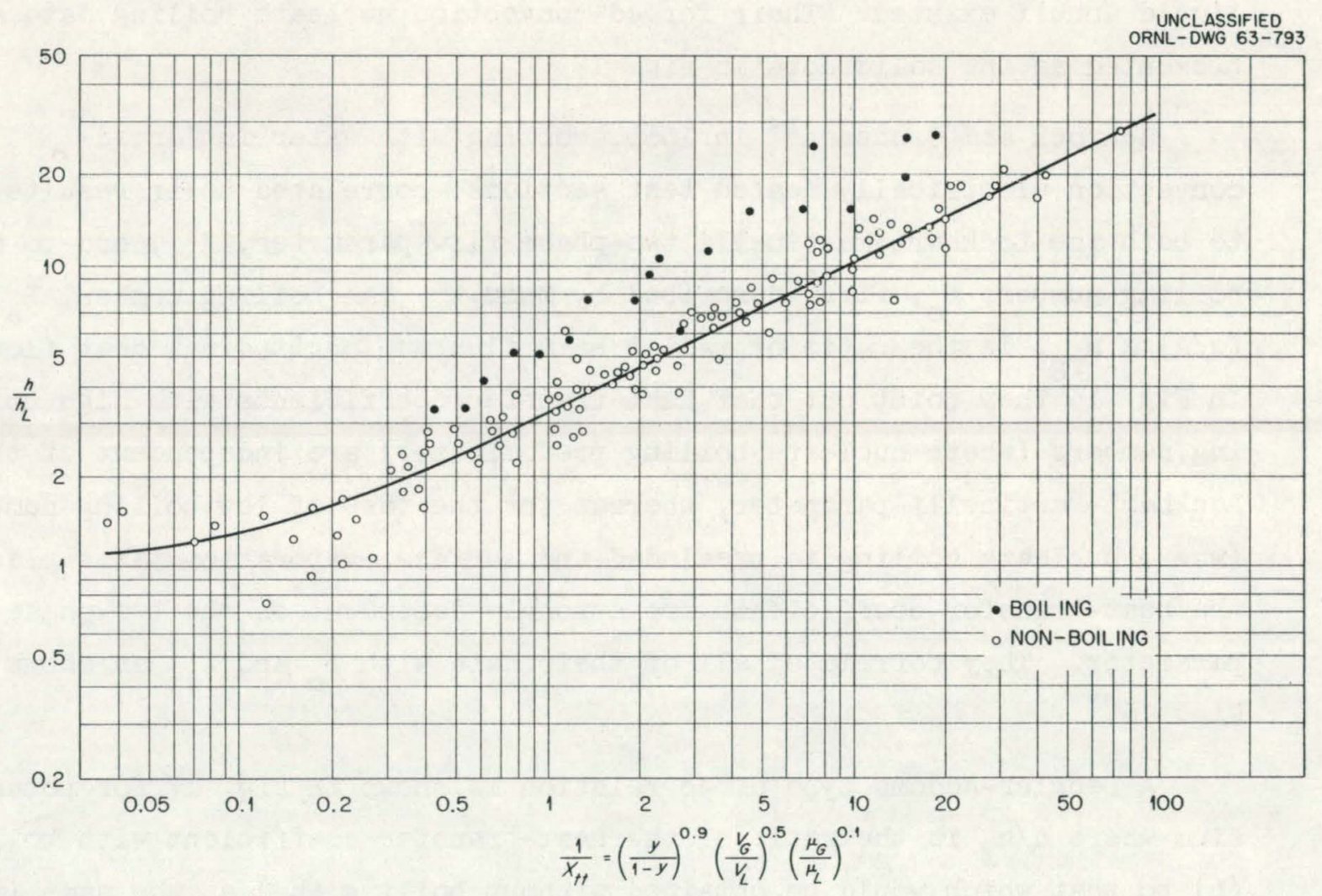

Fig. 14. Ratio of Heat-Transfer Coefficient as a Function of the Lockhart-Martinelli Two-Phase Parameter. 


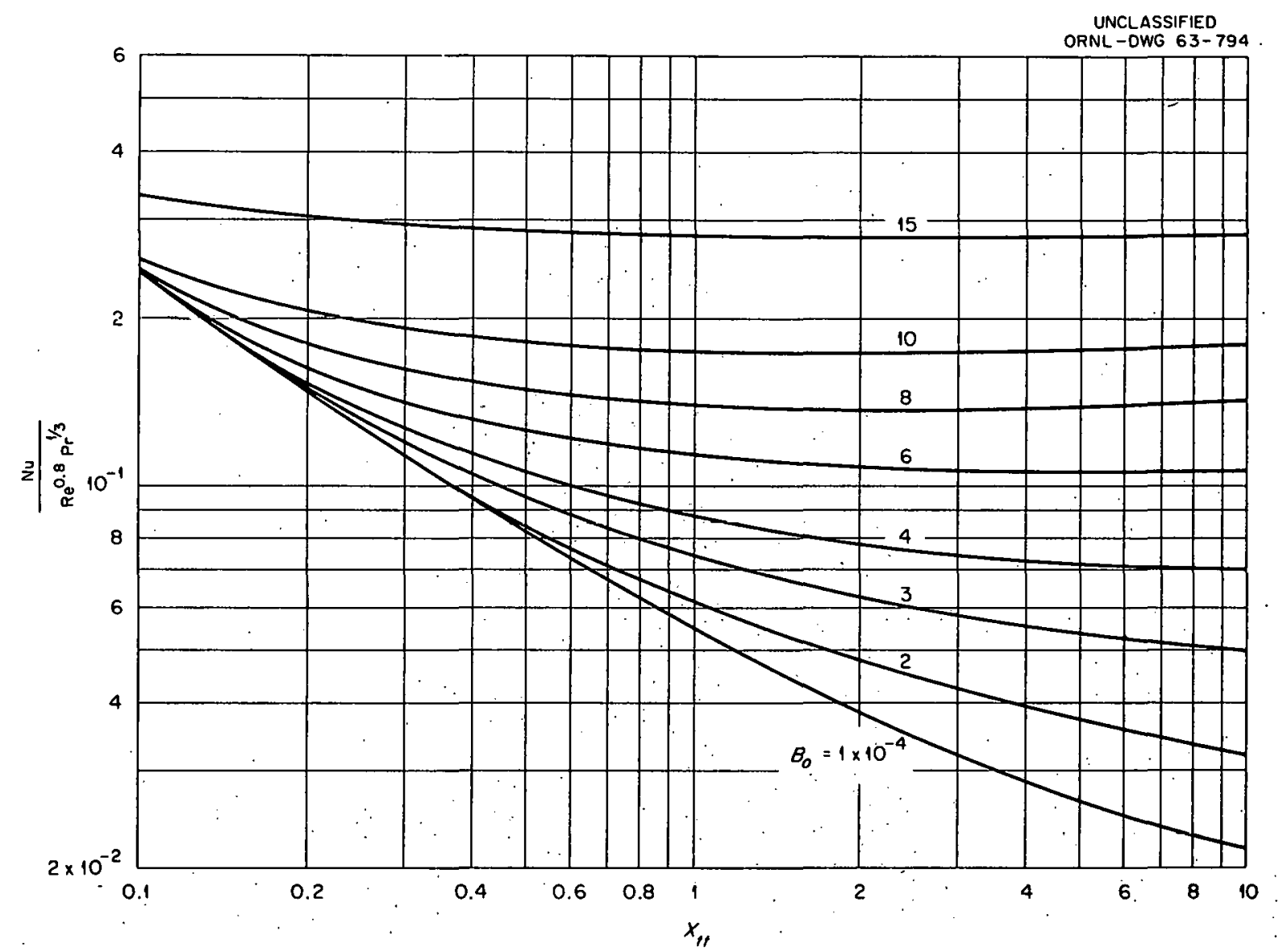

Fig. 3.5. Effect of Boiling Number and the Lockhart-Martinelili TwoPhase Parameter on Heat 'I'ransfer. 


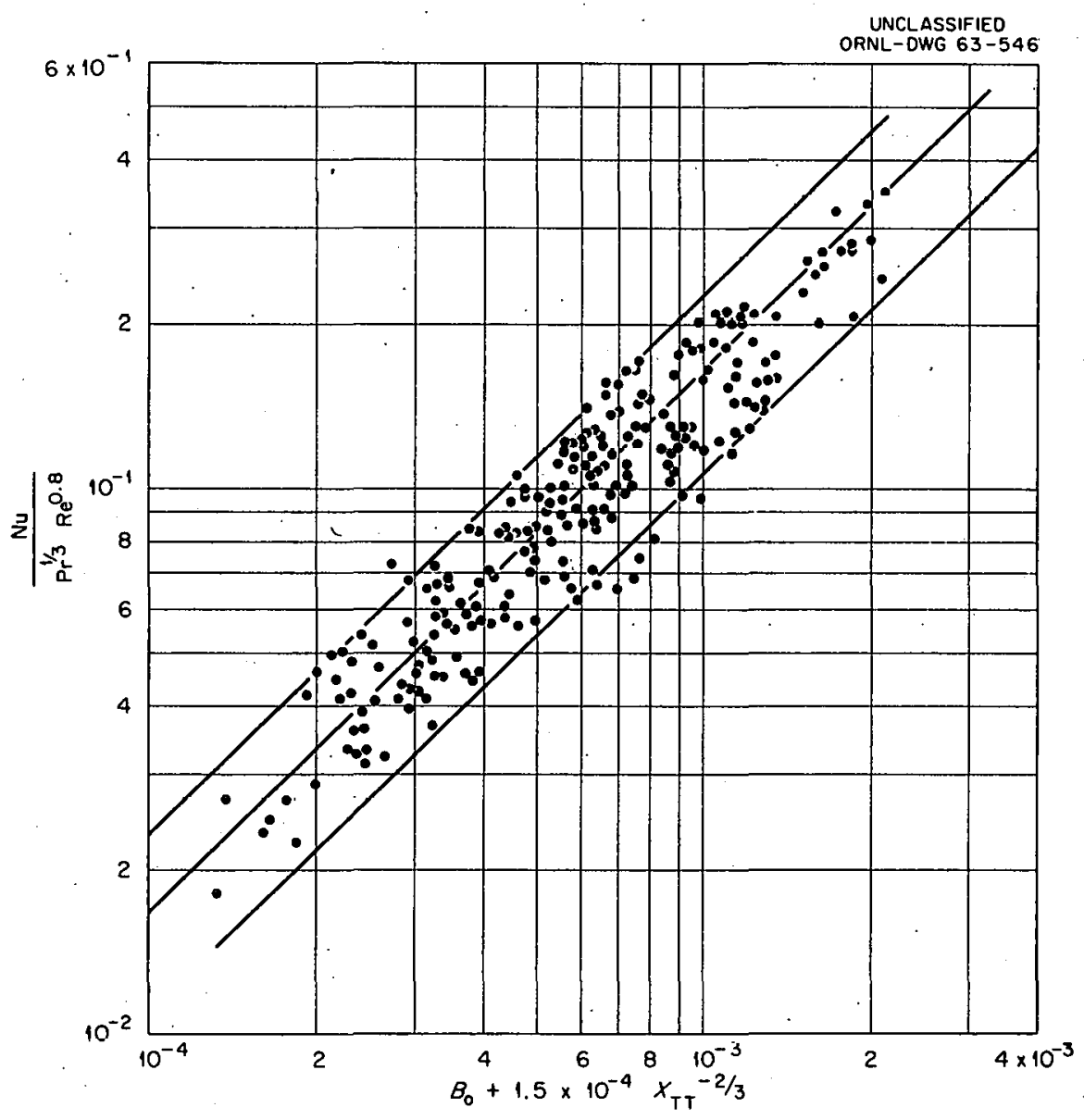

Fig. 16. Heat-Transfer Rate as a Function of Bciling Number and the Two-Phase Parameter of Lockhart and Martinelli. 


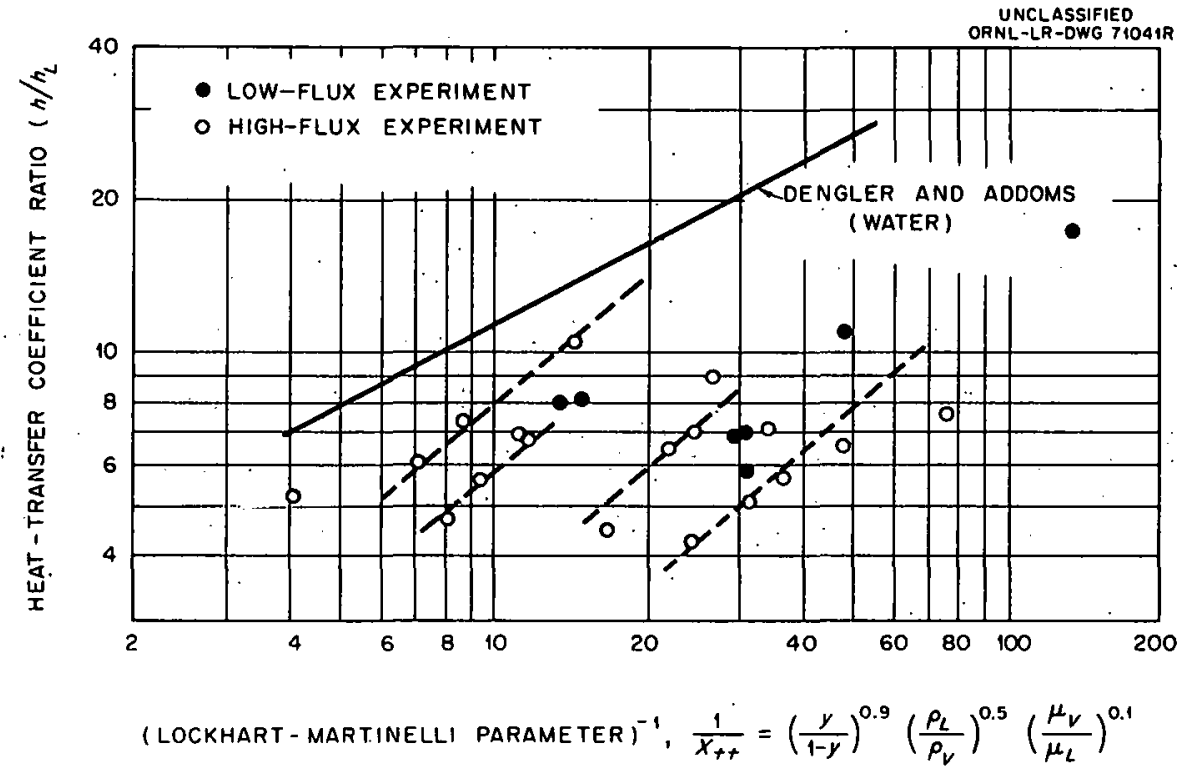

Fig. 17. Ratio of Boiling to Nonboiling Coefficients as a Function of the Twom Phase Flow Parameter. 
Since, under corresponding conditions, heat-transfer coefficients for nonboiling potassium are much greater than those for nonbolling water, it is not surprising that for the liquid metal the gain in the heat-transfer coefficient due to boiling is only one-third that found with water.

\section{CAVITY SIZE CALCULATIONS}

If a superheat of $10^{\circ} \mathrm{F}$ is desirable in a boiling-liquid-metal system, then by Eq. (3) the calculated cavity radius to sustain boiling from a surface submerged in $\mathrm{K}, \mathrm{Na}, \mathrm{Rb}$, and $\mathrm{Cs}$ is $0.94,1.87,0.77$, and $0.52 \times 10^{-3}$ in., respectively. Although a cavity of the rementrant type shown in Fig. Ilb is desirable, an alternate cavity such as that shown in Fig. 18c may be readily made by drilling a hole of the desired diameter to a depth of $\geq 0.008 \mathrm{in}$. and "sandblasting". with stainless steel particles to peen the mouth. A deeper cavity would take advantage of the temperature gra. dient through the heated wall and tend to offset Professor Bankoff's apprehension that liquid capillary pressure tends to deactivate a cavity during the interval between bubble release and the formation of a new one.

\section{RECOMMENDATIONS}

In view of the above analysis, it is recommended that:

1. The sheath of rod-type heaters immersed in potassium be drilled by Elox or other methods to a depth of $\geq 0.008$ in. (diameter 0.004 in.) and "sandblasted" to peen the mouth to a diameter of 0.002 in. (Fig. 18c). These holes should be drilled $\sim 1 / 4$ in. downstream from the beginning of the heated length.

2. In tubular boilers heated by clamshell-type heaters, holes can be drilled through the wall and subsequently welded and "sandblasted" as show in Fig. 18a; and alternate cavity is shown in Fig. 18b. Preferably, the cavities should be in the small-diameter tube section of the preheater to establish two-phase flow prior to boiler entry. Nucleation. should be initiated in a small-volume section of the loop, thus minimizing the pressure perturbations caused by nucleation. 


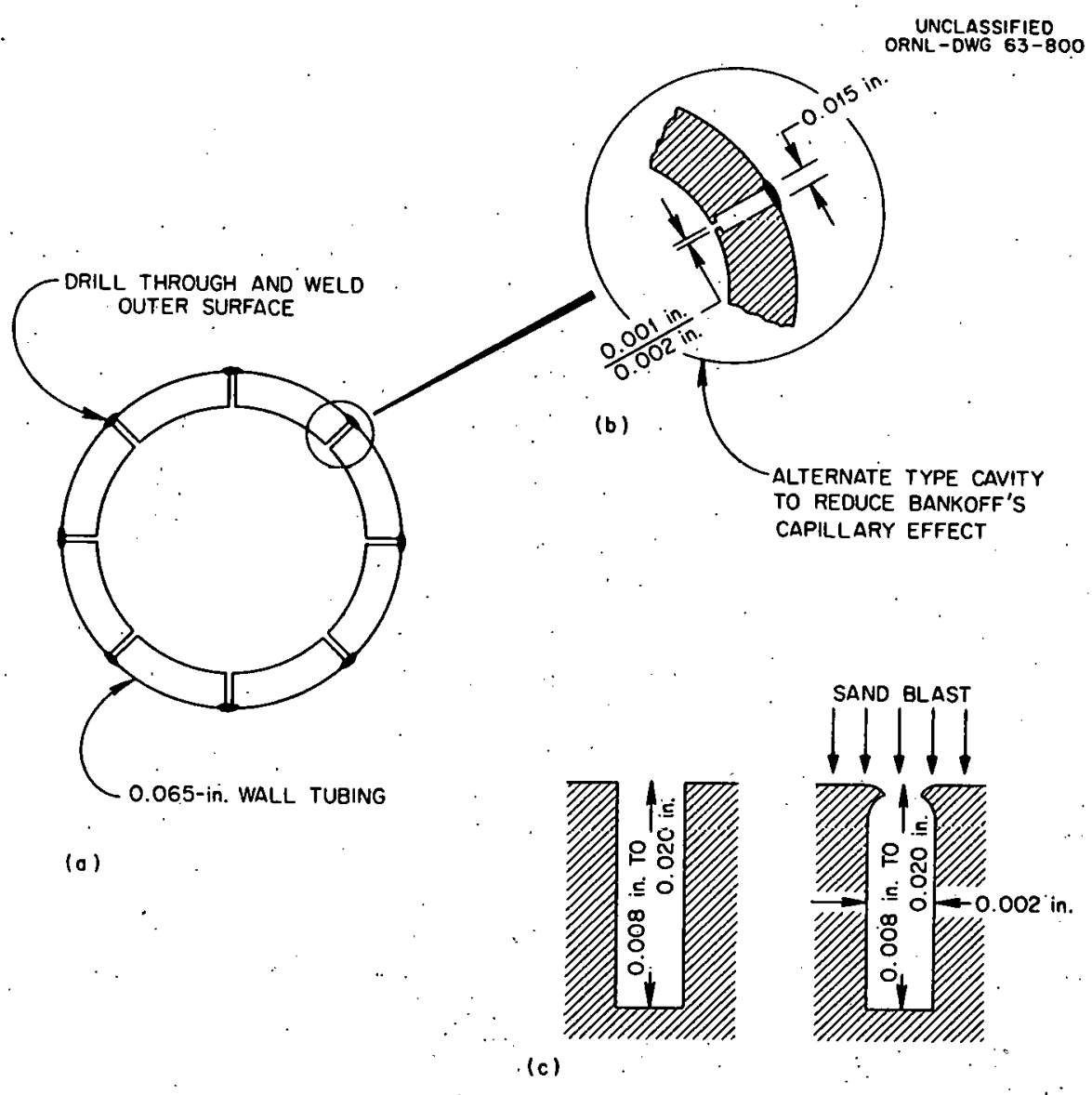

F1g. 18. Recommended Cavity Sizes and Shapes for Nucleation in a Boiling Potassium System. 
3. Delineate for potassium a curve similar to that in Fig, 2 and regime III portion of Fig. 4 .

4. A program of evaluating the superheat required to initiate boilm ing and to test $\mathrm{Eq}$. (3) with potassium would be of interest in the study of liquid-metal boiling.

The assumptions and correlations presented here are admittedly over. simplified; they are primarily presented to emphasize the difference between two-phase liquidmetal heat transfer and two phase heat transfer for ordinary fluids. It is hoped that this paper will provoke more thought and effort for a more quantitative study of boiling-liquid-metal heat transfer.

\section{REFTERENCES}

1. S. Nukiyama, Mech. Eng. Japan, 37(206): 367 (1934).

2. A. Heidrich, Dissertation, Techn. Hochschule, Aache, 1931 (reference from M. Jakob, Heat Transfer, Vol。 1; John Wiley and Sons, Inc, , New York, 1949)。

3. M. Ellion, "Study of Mechanism of Boiling Heat Transfer, " Jet Propulsion Laboratory Memorandum 20×88, March 1954.

4. P. Griffith and JoD. Wallis, "The Role of Surface Conditions in Nucleate Boiling," Chemical Bngineering Symposium Series, Vol. 56, No. 30, pp. 49-63, 1960。

5. P. Berenson, ${ }^{10}$ Transition Boiling Heat Transfer from a Horizontal Surface, "SCD Thesis, Mechanical Engineering Department, Massachusetts Institute of Technology, Cambridge, Mass。, 1960; also MIT Tech. Rept. No. 17, Heat Transfer Laboratory, Massachusetts Institute of Technology, March 1960。

6. E. A. Farber and R。 L。 Scorah, "Heat Transfer to Water Boiling under Pressure," Trans.Am。Soc。Mech。Engrs., 70(4): 369-384 (May 1948)。

7. M. Jakob, Heat Transfer, Vol。 I, P. 633, John Wiley and Sons, Inc。, New York, 1949.

8. M. W. Rohsenow, "'Heat Transfer with Boiling, "Notes for Modern Developments in Heat Transfer, MIT Sumer Session, Massachusetts Institute of Technology, Cambridge, Mass., 1960。 
9. C. Corty and A. S. Foust, "Surface Variables in Nucleate Boiling," Chemical Engineering Symposium Series, Vol. 51, No. 17, pp. 1-12, 1955 .

10. P. A. Nelson, "Heat Transfer to Boiling Metal by Convection," USAEC Report ANL-6507, Argonne National Laboratory, June 1961 (Classified).

11. E. E. Hoffman, Oak Ridge National Laboratory, personal communication to A. I. Krakoviak, Oak Ridge National Laboratory, February 1963.

12. N. A. Radovcich and R. Moissis, "The Transition from Two Phase Bubble Flow to Slug Flow," MIT Report No. 7-7673-22, Department of Mechanical Engineering, Massachusetts Institute of Technology, June 1962.

13. C. E. Dengler and J. M. Addoms, "Heat Transfer Mechanism for Vaporization of Water in a Vertical Tube," Chemical Engineering Symposium Series, Vol. 52, No. 18, pp. 95-103, 1956.

14. V. E. Schrock and L. M. Grossman, "Forced Convection Boiling in Tubes," Nuclear Sci. and Eng., 12: 474-481 (1962).

15. J. F. Mumm, "Heat Transfer to Boiling Water Forced Through a Uniformly Heated Tube," USAEC Report ANL-5276, Argonne National Laboratory, November 1954.

16. H. A. Johnson, J. P. Hartnett, and W. J. Clabaugh, "Heat Transfer to Lead-Bismuth and Mercury in Laminar and Transition Pipe Flow," Inst. Eng. Research, University of California, August 1953. 
i

THIS PAGE

WAS INTENTIONALLY

LEFT BLANK 
INTERNAL DISTR IBUTION

\author{
1. S. E. Beall \\ 2. M. Bender \\ 3. A. L. Boch \\ 4. R. B. Briggs \\ 5. R. D. Bundy \\ 6. J. W. Cooke \\ 7. D. M. Eissenberg \\ 8. L. W. Evers \\ 9. J. Foster \\ 10. A. P. Fraas \\ 11. L. C. Fuller \\ 12. W. R. Gambill \\ 13. B. L. Greenstreet \\ 14. A. G. Grindell \\ 15. E. E. Hoffman \\ 16-20. H. W. Hottman \\ 21. J. K. T. Jung \\ 22. J. J. Keyes, Jr. \\ 23. G. J. Kidd, Jr. \\ 24. R. B. Kor smeyer \\ 25-30. A. I. Krakoviak \\ 31. M. E. LaVerne \\ 32. C. G. Lawson \\ 33. R. N. Lyon \\ 34. H. G. MacPherson
}

35. R. E. MacPherson

36. W. D. Manly

37. J. W. Michel

38. A. J. Miller

39. R. C. Olson

40. A. M. Perry

41. M. W. Rosenthal

42. W. K. Sartory

43. H. W. Savage

44. A. W. Savolainen

45. M. J. Skinner

46. I. Spiewak

47. J. A. Swartout

48. D. G. Thomas

49. D. B. Trauger

50. J. L. Wantland

51. R. P. Wichner

52. M. M. Yarosh

53. J. Zasler

54-55. Central Research Library (CRL)

56-58. Y-12 Document Reference Section (DRS)

59-106. Laboratory Records Department (IRD)

107. Laboratory Records Department -

Record Copy (IRD-RC)

108. Reactor Division Library, Bldg. 9204-1

EXTTERNAL DISTRIBUTION

109-123. Division of Technical Information Extension (DTIE)

124. Research and Development Division, ORO

125-126. Reactor Division, ORO 